\title{
Fantasias freudianas: aspectos centrais e possível aproximação com o conceito de esquemas de Aaron Beck
}

\author{
Lara Cristina D'Avila Lourenço - Universidade Federal de São Paulo - Campus Baixada Santista, São Paulo, Brasil \\ Ricardo da Costa Padovani - Universidade Federal de São Paulo - Campus Baixada Santista, São Paulo, Brasil
}

\begin{abstract}
Resumo
Este artigo aborda pontos sobre o conceito de fantasia, de Sigmund Freud, e propõe um diálogo entre eles e o conceito de esquemas, proposto pela teoria da terapia cognitiva de Aaron Beck. Essa sugestão não indica ecletismo teórico ou prático, abordando esses conceitos considerando as diferenças dos seus pressupostos. De acordo com a teoria freudiana, as fantasias representam uma forma de leitura subjetiva, organizada a partir dos desejos e dos mecanismos de defesa, da realidade dos fatos. Trata-se do que Freud denomina realidade psíquica, a qual tem suas bases na infância e nas fantasias filogenéticas. A teoria de Beck não faz referências à noção de fantasia, contudo considera o papel das impressões e das interpretações subjetivas dos eventos, especialmente aqueles vividos na infância. Assim desenvolve a tese de que os esquemas organizam processos cognitivos, afetivos e comportamentais. O diálogo entre tais teorias tem sido corroborado por estudos das ciências cognitivas.

Palavras-chave: Fantasia, Psicanálise, Esquemas, Cognitiva.
\end{abstract}

The Freudian fantasies: central aspects and possible approaches with concepts of Aaron Beck's schemes

\begin{abstract}
This article discusses points about the concept of fantasy of Sigmund Freud, and suggests a dialogue between them and the concept of schemes proposed by Aaron Beck's cognitive therapy theory. This suggestion does not indicate any form of eclecticism, theoretical or practical, and discusses these concepts considering the differences in their assumptions. According to Freudian theory, the fantasy represents a form of subjective reading, organized from the wishes and defense mechanisms, of facts' reality. This is what Freud called psychic reality, which has its basis in childhood and the phylogenetic fantasies. Beck's theory does not make references to the notion of fantasy, however, and considers the role of subjective impressions and interpretations of events, especially those experienced in childhood. Thus, he develops the thesis that the schemes organize cognitive, affective and behavioral processes. The dialogue between these theories has been supported by studies in cognitive science.

Keywords: Fantasy, Psychoanalysis, Schemes, Cognitive.
\end{abstract}

Fantasías freudianas: aspectos centrales y posible aproximación con el concepto de esquemas de Aaron Beck

\begin{abstract}
Resumen
Este artículo discute los puntos sobre el concepto de fantasía, de Sigmund Freud, y se propone a un diálogo entre ellos y el concepto de esquemas propuesto por la teoría de la terapia cognitiva de Aaron Beck. Esa sugerencia no significa eclecticismo teórico o práctico y aborda estos conceptos teniendo en cuenta las diferencias en sus suposiciones. Según la teoría freudiana, las fantasías representan una forma de lectura subjetiva, organizada a partir de los deseos y de los mecanismos de defensa, de la realidad de los hechos. Se trata de lo que Freud llamó de la realidad psíquica, la cual tiene sus bases en la infancia y en las fantasías filogenéticas. La teoría de Beck no hace referencia a la noción de fantasía, sin embargo, considera el papel de las impresiones y de las interpretaciones subjetivas de los acontecimientos, especialmente aquellos vividos en la infancia. Así se desarrolla la tesis de que los esquemas organizan procesos cognitivos, afectivos y comportamentales. El diálogo entre esas teorías ha sido apoyado por estudios de las ciencias cognitivas. Palabras clave: Fantasía, Psicoanálisis, Esquemas, Ciencia Cognitiva.
\end{abstract}

Este artigo aborda pontos fundamentais sobre o conceito de fantasia, na obra de Sigmund Freud, e propõe um diálogo entre eles e o conceito de esquemas, apresentado pela teoria da terapia cognitiva, elaborada por Aaron Beck. Cumpre notar que essa proposta não indica ecletismo teórico ou prático, e apresenta tais conceitos considerando sempre as diferenças dos pressupostos que os fundamentam. Tal objetivo tem interesse didático, bem como pode colaborar para novos debates e desdobramentos teóricos. Vale considerar, contudo, que não é pretensão deste artigo apresentar todas as especificidades do conceito de esquema, que engendra as propostas das terapias cognitivas, bem como do conceito de fantasia presente nas diferentes formulações da psicanálise.
As elaborações sobre as fantasias não somente estão na gênese da teoria de Freud, mas também sustentam seu desenvolvimento e, pode-se dizer, constituem-se como núcleo instransponível até seu final. Da mesma forma, o conceito de esquemas encontra-se nos fundamentos, bem como nos desdobramentos das terapias cognitivas.

Com efeito, as declarações freudianas sobre as fantasias confundem-se com a própria afirmação da realidade psíquica, que marca o início das teses psicanalíticas; também é possível afirmar que a temática da fantasia não está ausente nos textos (especialmente aqueles datados do período de 1891 a 1900) em que Freud tenta definir e localizar a dinâmica entre as representações psíquicas e as percepções, 
particularmente por meio das hipóteses sobre a memória, os sonhos e as alucinações. E quando a teoria psicanalítica estava fortemente consolidada, especialmente quando a repressão é entendida como mecanismo de defesa primordial (Freud, 1915, 1980a), a fantasia pode ser vista como retorno do reprimido, cujo conteúdo deve ser decifrado pelo tratamento clínico. A universalidade e tipicidade das fantasias, bem como suas resistências às intervenções clínicas (Freud, 1937/1980b), são explicadas por meio da complexa noção de fantasias filogenéticas, que ocupam o pensamento desse autor até seus últimos escritos.

$\mathrm{Na}$ teoria da terapia cognitiva, proposta por Beck (1963, 1964), não há referências explícitas à noção de fantasia. Contudo, além da formação psicanalítica do autor, vários fatores o levam a considerar o papel das interpretações subjetivas dos eventos, cujos arranjos compõem as estruturas cognitivas denominadas esquemas. Entre tais fatores merecem destaque: a chamada revolução cognitiva nas décadas de 50 e 60; os escritos sobre os construtos cognitivos, de George Kelly, Albert Ellis e Jean Piaget; as reações da comunidade clínica e científica ao modelo estritamente comportamental; e o questionamento, feito pelo autor, do modelo clínico psicodinâmico (Beck, 2005a, 2005b; Knapp \& Beck, 2008).

Segundo Beck (Beck e cols., 2005b; 1997) a ativação de estruturas cognitivas idiossincráticas, denominadas esquemas, exerce papel central na determinação de sintomas cognitivos, emocionais e comportamentais. Sem dúvida, essa teoria não desconsidera os aspectos afetivos, mas privilegia a análise e a modificação de padrões cognitivos disfuncionais, subjacentes aos quadros psicopatológicos. Beck (1963, 1964, 2005a) entende que a aquisição de padrões cognitivos realistas determina a emergência de novas respostas emocionais e comportamentais.

Em síntese, de acordo com a teoria freudiana, as fantasias representam uma leitura subjetiva da realidade dos fatos, organizada a partir dos desejos e dos mecanismos de defesa do indivíduo. $\mathrm{E}$ a origem dessas fantasias, o autor encontra no que denomina préhistória do indivíduo e da espécie (ou seja, nas vivências da infância e nos primórdios da humanidade, respectivamente). Segundo a teoria da terapia cognitiva (Alford \& Beck, 1997; Beck, 2005ª 1964; Knapp \& Beck, 2008), os esquemas são formados desde a infância, a partir do modo como o indivíduo conhece e interpreta os eventos fundamentais de sua experiência. Além do conteúdo representacional, os esquemas apresentam valência afetiva, permeabilidade, flexibilidade, amplitude. E se Freud privilegia o papel dos afetos e da sexualidade nesse processo, e Beck, o da cognição, não está excluído o fato de que tanto as fantasias quanto os esquemas constituem espécies de roteiros, por meio dos quais o indivíduo realiza suas experiências. E assim, conhecê-los e reorganizá-los são tarefas fundamentais das clínicas orientadas por tais teorias.

Vale considerar que afeto e cognição não são conteúdos absolutamente separados, para ambos os autores. Afinal, Freud (1950/1980c) primordialmente designa por afeto o processo que compreende a descarga das excitações e seus resultados psíquicos. Isto é, os caminhos dos afetos estão nas bases dos processos mnêmicos. Beck (1964) salienta que esquemas cognitivos são organizadores dos comportamentos do indivíduo, na medida em que são carregados de afeto. Mas o afeto, por sua vez, pode ser entendido como uma espécie de resposta, elaborada a partir de conteúdos cognitivos específicos: "A resposta afetiva é determinada pela forma como um indivíduo estrutura sua experiência" (Beck, 1964, p. 567). Dessa maneira, quando uma resposta afetiva inapropriada se apresenta em determinada situação, a incongruência pode ser atribuída a um esquema particular que foi evocado.

É também importante advertir que as noções de afeto e de cognição têm distinções fundamentais, conforme apresentadas por Freud e por Beck. Para aquele, o afeto está baseado no conceito de pulsão (especificamente pulsão sexual), e a cognição inclui processos inconscientes (notando que o inconsciente, nesse caso, é definido enquanto instância psíquica, com formas próprias de funcionamento e cujo núcleo é inacessível à consciência). Para Beck, o afeto é produto de esquemas cognitivos, porém um mecanismo circular pode ser visto entre ambos: os esquemas cognitivos determinam os afetos, e estes reforçam as atividades de tais esquemas. Embora afirme que alguns processos cognitivos podem não ser conscientes (especialmente aqueles que se apresentam conforme os chamados pensamentos automáticos), Beck não se refere ao inconsciente enquanto instância psíquica. Ou seja, os processos inconscientes, para esse autor, não têm uma forma de funcionamento própria e não são necessariamente inacessíveis à consciência. Portanto, nesse caso, seria melhor falar em pré-consciente (Alford \& Beck, 1997).

É justamente em torno da questão sobre o privilégio dos afetos ou dos processos cognitivos que Beck afasta-se de sua formação psicanalítica. Ao analisar o mecanismo da depressão, ele enfatiza o processo cognitivo desse quadro clínico. Segundo ele, a psicanálise não considera em sua totalidade os aspectos cognitivos da depressão, entendendo-a primordialmente como transtorno afetivo. Beck (1963) 
entende a depressão como transtorno do pensamento e amplia a discussão afirmando que transtornos do pensamento são subjacentes a todas as psicopatologias. Sem a pretensão de se debruçar sobre esse tema, este artigo apenas nota que as conclusões de Beck sobre a depressão deixam evidente a supremacia da cognição em seu modelo teórico (Alford \& Beck, 1997; Beck, 1963, 1964).

\section{As fantasias de sedução e o complexo de Édipo, na obra de Frend}

O comportamento humano obedece a certos roteiros, versões psíquicas da realidade dos fatos, as quais têm um núcleo inconsciente: essa tese encontrase nos fundamentos da psicanálise propriamente dita. Os precursores dessa tese são os relatos das pacientes histéricas, que ocupam Freud desde o início de sua prática clínica. A partir de tais relatos, os autores (Breuer \& Freud, 1895/1980) concluem que na gênese dos sintomas histéricos estariam cenas traumáticas de cunho sexual, das quais essas pacientes teriam sido vítimas na infância. Tais cenas, por não terem recebido significação e reação adequadas nos momentos de suas ocorrências, teriam permanecido como pontos de fixação, excluídos da consciência. Inconscientes, essas cenas seriam repetidas simbólica e compulsivamente mediante sintomas histéricos (Freud, 1950/1980c).

Entretanto, em 1897, em uma carta a Fliess, Freud (1950/1980d) confessa não mais acreditar na veracidade de tais relatos; ou melhor, ele não mais os entende como realidade dos fatos, mas como realidade psíquica. Tem-se início o conceito de fantasia inconsciente: a realidade dos fatos vista e interpretada conforme os recursos psíquicos e desejos do indivíduo. Longe de mentir, as histéricas mostram que, ao se colocarem como vítimas, estão se defendendo da própria excitação sexual, a qual seria alvo de suas censuras. Ou seja, além do aspecto de defesa, tais fantasias de sedução também seriam formas representativas do desejo inconsciente.

Dessa maneira, está afirmada a presença da sexualidade infantil (isto é, ela não é despertada em razão do ato perverso de algum adulto, mas inerente à infância). Contudo, Freud não exclui totalmente a presença da sedução. Como nota Monzani (1989), ao se referir ao movimento do pensamento freudiano, o que acontece é que a sedução deixa de ser vista como um ato perverso e pontual, para tornar-se difusa e inerente às relações de afeto e cuidados que os adultos dispensam à criança.

Para a psicanálise, as fantasias de um indivíduo são sempre constituídas a partir da leitura e introjeção $\mathrm{da}$ rede de fantasias daqueles que o cercam (especificamente, daqueles que compõem suas relações amorosas primordiais, ou seja, dos que cumprem as funções parentais). Com efeito, é a afirmação das fantasias inconscientes que leva Freud às teses sobre o "complexo de Édipo". Isso acontece na medida em que esse autor conclui que as fantasias de sedução, relatadas pelos pacientes apresentam um roteiro específico subjacente, o qual sempre diz respeito às relações de afeto entre a criança e o casal parental.

O complexo de Édipo pode ser visto como um conjunto de fantasias inconscientes, ou ainda, como teorias tecidas pelas crianças em suas interpretações de temas como: a distinção e a excitação sexual; o funcionamento do próprio corpo; a origem dos bebês e a própria origem, portanto (D'Avila Lourenço, 2000). É por meio dessas teorias que a criança inicia suas relações amorosas em uma posição masculina ou feminina. E o que daria nuances individuais a esse processo seria o que o autor entende por "fatores complementares", ou seja, a inter-relação entre fatores inatos e acidentais na constituição psíquica (o peso e a maneira como tais fatores se complementam é um enigma não respondido pela psicanálise, admite Freud).

A formação e vivência das fantasias edípicas aconteceriam numa cronologia específica, entre três e seis anos de idade, aproximadamente (Freud, 1905/1980e). Nesse momento, seria formado o que o autor (Freud, 1912/1980f) denomina "clichê estereotípico", espécie de protótipo das relações afetivas. $\mathrm{Ou}$ seja, em tais fantasias o sujeito representaria sua posição diante do objeto de amor, a qual seria inconscientemente repetida nas relações amorosas futuras. Essa repetição seria tanto mais rígida, conforme a existência da psicopatologia.

No tratamento, tratar-se-ia então de desvendar tais protótipos das relações amorosas, para que o indivíduo tenha consciência $\mathrm{da}$ repetição e possa reorganizar os roteiros de suas fantasias. Tal desvendamento e reorganização aconteceriam por meio da "transferência" (Freud, 1912/1980f): na relação com o analista, o paciente atuaria esse protótipo de relação afetiva. Tal repetição, no setting específico do tratamento analítico, daria ao analista as indicações do curso psíquico do paciente e a oportunidade de manejar adequadamente a transferência. Isso permitiria ao paciente a consciência e certa modificação dessas formas estereotipadas de relacionamento.

Em 1937, portanto ao final de sua obra, Freud (1937/1980b) admite que os tratamentos psicanalíticos, no que tange ao objetivo de elaborar e superar as fantasias edípicas, têm limite. As explicações dessa limitação tocam em pontos complexos da obra do autor, especialmente naquele que se refere às "fantasias filogenéticas", as quais Freud fundamenta a partir de sua leitura de Darwin e da chamada teoria da herança 
dos caracteres adquiridos (Ritvo, 1992). De acordo com essa formulação teórica, as experiências pelas quais diversas gerações sucessivas passam tornam-se herança da espécie. As fantasias em torno do complexo de Édipo se ligariam às experiências vividas pela humanidade em seus primórdios. Esse fundo filogenético seria instransponível pela psicanálise, o que sem dúvida relativiza os alcances da clínica psicanalítica (D'Avila Lourenço, 2005a).

Aliás, é possível pensar que, para Freud (1923/1980g), o núcleo do inconsciente é algo hipotético e inatingível psiquicamente. Primeiro, porque ele toca em bases biológicas, exatamente no ponto em que biológico e psíquico se perpassam; o que, para Monzani (1989), leva Freud a formalizar o conceito de id. Segundo, porque o aparelho psíquico é definido na dualidade entre inconsciente e consciente (com efeito, qualquer hipótese sobre a consciência absoluta é ausente da teoria freudiana).

\section{As fantasias freudianas e a dinâmica da repressão}

As fantasias nem sempre são conscientes e, se o são, o indivíduo na maior parte das vezes não sabe decifrar seus conteúdos. Isso é explicado por meio do mecanismo da repressão: nas bases do inconsciente há desejos reprimidos, expressos inclusive por meio de fantasias, as quais permanecem excluídas da consciência ou, se a atingem, é com a condição de não estarem decifradas.

Vale notar que a repressão ocorre quando a satisfação da pulsão, prazerosa em si, causaria desprazer maior em virtude de interesses contrários e concomitantes na mente. Ou seja, a repressão pressupõe uma divisão na mente, especificamente, a divisão entre consciente e inconsciente, uma vez que a essência da repressão consiste em inibir (ou suprimir) a pulsão, afastando sua representação da consciência. Nesse ponto, interessa esclarecer o que Freud entende por pulsão e seus representantes: em termos breves, a pulsão é definida como o representante dos estímulos endógenos (Freud, 1915/1980a). O que representa a pulsão é um conjunto ideativo que, por ser expressão direta das tensões somáticas e organizado de acordo com a história do sujeito, é acompanhado de uma carga afetiva (D'Avila Lourenço, 2005b).

E o autor (Freud, 1915/1980a) supõe a existência de uma repressão primeva, sempre inacessível à consciência (justamente na medida em que marca a divisão entre as instâncias consciente e inconsciente) e que estabeleceria um ponto de fixação para futuras repressões. Esse ponto seria o primeiro representante reprimido da pulsão. Os derivados desse representante se tornariam alvo da repressão propriamente dita, ou melhor, da repressão cujos efeitos podem ser observados na clínica. De qualquer forma, a ideia de repressão primeva nunca é muito clara para Freud. E em 1926, ele levanta a hipótese de que as repressões são realizadas para evitar a angústia, a qual é consequente a traumas ou à iminência deles. A primeira situação traumática seria vivida na ocasião do nascimento; nesse caso, tratar-se-ia de um trauma unicamente fisiológico, que produziria angústia somática (Freud, 1926/1980h).

De acordo com essa hipótese, a primeira repressão traria a marca do desamparo biológico, diante do excesso de estímulos no nascimento. Tal desamparo, porque só aliviado mediante a presença de um ser humano cuidador, desdobrar-se-ia em desamparo psíquico. Freud (1926/1980h) esclarece que, desde muito cedo, o ser humano entende que, para amenizar o desamparo, não basta a presença de outro ser humano protetor, mas é também necessário que esse outro esteja voltado para ele, que o ame. Assim, o risco da perda do amor do outro torna-se fonte principal de angústia. Em outras palavras, a angústia diante do risco da perda do amor do outro é motor das repressões. Dessa maneira, os representantes pulsionais reprimidos são, em especial, aqueles que representam desejos que colocariam em risco o amor do outro ser humano.

Quando os representantes pulsionais, sob repressão, são investidos com alta carga de afeto, criase seu acesso à consciência. Contudo, esse acesso deve obedecer a certa condição, qual seja, um grau de distorção nos referidos representantes, suficiente para que a consciência não perceba a manifestação do conteúdo reprimido (Freud, 1915/1980a). Se essa distorção não é suficiente, a repressão falha em seu propósito, que é o de evitar a angústia. Dessa forma, a angústia é justamente o sinal para que a repressão seja reforçada.

Assim o caráter enigmático das fantasias está de acordo com a função da repressão. Isso, em grande parte, explica as resistências do paciente ao tratamento que deve, portanto, trabalhar no sentido de diminui-las, desvendando os conteúdos reprimidos (salientando que, conforme as definições da repressão primeva, sempre há limite nesse desvendamento).

Os desejos edípicos são particularmente alvos da repressão. São eles que, cumpre enfatizar, Freud encontra subjacentes às fantasias de seus pacientes. Nesse ponto, vale citar o comentário do autor, a respeito de uma das fantasias obsessivas de seu paciente, conhecido como Homem dos Ratos (Freud, 1909/1980i): Por exemplo, uma das mais antigas e preferidas obsessões do paciente [...] tinha o seguinte contexto: "Se eu casar com a dama, a meu pai ocorrerá algum infortúnio (no outro mundo)" [itálico do autor]. 
Introduzindo os elementos intermediários, que foram omitidos mas que conhecemos da análise, obtemos a seguinte corrente de pensamento:

Se meu pai estivesse vivo, ele estaria tão furioso com minha intenção de casar-me com a dama como esteve na cena de minha infância; de modo que en teria outra explosão de raiwa contra ele, desejando-lhe todo mal possivel; e graças à onipotência de meus desejos esses males acabariam inevitavelmente por incidir sobre ele. (Freud, 1909/1980i, p. 228)

Essa citação evidencia o funcionamento dos pensamentos inconscientes, os quais são fundados em processos pulsionais.

Esquema, no modelo teórico proposto por Aaron Beck

O próprio Beck (Beck e cols., 1997, 2005a) identifica a influência da filosofia estoica na formulação da sua teoria, especificamente no que concerne à tese de que o que perturba o homem não são os fatos, mas a interpretação feita deles. Neste cenário da supremacia da cognição, as respostas emocionais, motivacionais e comportamentais são determinadas a partir de estruturas cognitivas com conteúdos que se apresentam relativamente estáveis, denominadas esquemas. Os esquemas são compostos de representações (crenças) e proveem estabilidade aos sistemas cognitivo, afetivo e comportamental. Nessa perspectiva, enfatiza-se a investigação e validação de ideias e de crenças idiossincráticas a respeito de si, de suas experiências e do futuro, o que compõe o que foi definido como tríade cognitiva (Alford \& Beck, 1997; Beck e cols, 1997).

Beck (1963) nota que a importância dos processos cognitivos, especialmente vistos como interpretação dos fatos, também é encontrada nas ideias psicanalíticas. Nesse sentido, o autor (Beck, 1963) considera principalmente as noções freudianas de processos primários e processos secundários de funcionamento psíquico, as quais se referem a certo desenvolvimento nas formas de cognição, ou seja, à ideia de que os pensamentos racionais e elaborados estão fundados em um psiquismo arcaico e irracional (sobre isso ver Freud, 1911/1980j).

É como psiquiatra e psicanalista que, no final da década de 1950, Beck (1963) busca analisar empiricamente os critérios envolvidos nos quadros de depressão. Segundo o autor, a teoria de Freud entenderia a depressão como consequência da agressividade do indivíduo dirigida contra si, uma forma de autopunição, portanto. Nesse sentido, Beck (Beck \& cols., 1997, 1963/1964) observa os conteúdos oníricos de seus pacientes e conclui que eles são similares aos conteúdos de seus pensamentos em vigilia, os quais seriam então marcados pela autocrítica, pessimismo e negativismo. Tais pensamentos se apresentam como distorções da realidade (distorções cognitivas) e expressam interpretações negativas que o indivíduo tem de si, de suas experiências e de seu futuro (tríade cognitiva). Tais observações levam Beck (1963) à conclusão de que os transtornos de humor são, em essência, transtornos de pensamentos.

Além disso, Beck (Beck \& cols., 1997) observa que os pensamentos depressivos são experimentados pelos pacientes como respostas automáticas, involuntárias. Alford e Beck (1997), influenciados pelo conceito de processamento automático de informação (conceito proveniente da ciência e da psicologia cognitivas), afirmam que processos cognitivos podem ser explicados em termos de automatismo. E, nesse sentido, seria possível falar em pensamentos inconscientes. Entretanto, como dito na introdução deste artigo, a teoria de Beck não considera o inconsciente como instância psíquica. Os pensamentos automáticos são ditos inconscientes somente medida em que não são previstos ou controlados pelo indivíduo; porém, nada impede que tais conteúdos tornem-se conscientes. Nesse caminho, Beck afirma a necessidade de questionar as crenças do paciente, na qual o terapeuta teria êxito por meio do chamado empirismo colaborativo e por meio da técnica que denominou questionamento socrático (Padesky, 2010).

Os processos psicoterápicos, fundamentados a partir da investigação cuidadosa dos dados clínicos e do emprego de técnicas cognitivas e comportamentais específicas, permitiriam que os pacientes pudessem se antecipar às suas distorções cognitivas, assim como modificá-las. Apesar dessa proposta clínica, Beck (1963) observa que uma parcela significativa dos pacientes, embora consiga identificar os pensamentos depressivos, não consegue evitar que eles se manifestem antes que uma avaliação mais realista e coerente da realidade seja feita. Outra parcela nem mesmo consegue reconhecer que esses pensamentos são distorcidos. Essa constatação clínica, realizada ainda no início da teoria da terapia cognitiva de Beck, mostra que quando as estruturas cognitivas estão fortemente consolidadas, os tratamentos clínicos envolvem maiores dificuldades e tempo.

Sempre mantendo o papel central do conceito de esquemas, as terapias cognitivas realizaram avanços em suas formulações teóricas e técnicas, a saber: o conceito de modos proposto por Beck (2005b); a terapia focada no esquema, apresentando uma proposta integrativa de diferentes teorias psicológicas, entre as quais se destacam a gestalt e psicanálise (Young, Klosko \& Weishaar, 2008); a noção do processamento cognitivo inconsciente, formulada a partir da aproximação com as neurociências (Callegaro, 2005, 2011). 
Em relação aos tratamentos clínicos, a terapia cognitiva (Alford \& Beck, 1997; Beck, 1963; Beck \& cols., 1997; Knapp \& Beck, 2008) entende que paciente e terapeuta têm papéis colaborativos na elaboração do chamado plano terapêutico. Isso em nada lembra as direções da clínica freudiana, baseadas na associação livre (por parte do paciente) e na atenção flutuante (por parte do analista). Contudo, é interessante notar que Beck não desconsidera as manifestações e importância da transferência, em sua clínica:

Embora a transferência, conforme o conceito psicanalítico, não seja incentivada, sua manifestação pode ser uma ferramenta valiosa para demonstrar as distorções interpessoais do paciente. Da mesma forma, qualquer manifestação de resistência ao tratamento é lidada e tratada como crenças subjacentes disfuncionais (Knapp \& Beck, 2008, p. S59).

Notando que os padrões cognitivos são organizadores dos processos afetivos e comportamentais, Beck $(1963,1964)$ os entende como verdadeiros esquemas. Os esquemas funcionam como filtros, que orientam a seleção, a codificação, o armazenamento (memória) e a recuperação de informações do aparato cognitivo. Por meio dos esquemas, o organismo confere significados aos eventos e provê estabilidade aos sistemas cognitivos, afetivos e comportamentais.

Alguns esquemas podem estar latentes e ser ativados por eventos análogos às experiências nas quais eles foram formados. Quando ativados, e se disfuncionais, interferem na capacidade de avaliação objetiva dos eventos. Distorções cognitivas sistemáticas se apresentam à medida que esquemas disfuncionais são ativados (Alford \& Beck, 1997, Knapp \& Beck, 2008). Assim, o tratamento clínico exige que o terapeuta identifique e modifique os esquemas disfuncionais, que proveem a base para a interpretação das experiências da realidade objetiva.

\section{Considerações finais}

As fantasias e os esquemas cognitivos são construtos fundamentais, nas teorias e técnicas de Freud e de Beck, respectivamente. Para ambos os autores, os sintomas são organizados em torno desses conceitos, ou seja, a posição subjetiva é assumida e atuada com base nesses roteiros e interpretações primordiais.

Visto a importância dos esquemas e das fantasias, eles são focos dos tratamentos clínicos orientados por essas teorias. Mas a identificação e mudanças desses processos são pensadas de maneiras distintas por elas. As fantasias, segundo Freud, podem se tornar conscientes ou ter seus conteúdos decifrados. Contudo, pelo menos epistemologicamente, nenhum tratamento é capaz de ultrapassar as barreiras da chamada repressão primeva e da organização filogenética (D'Avila Lourenço, 2005a). De acordo com Beck (Alford \& Beck, 1997), os esquemas podem se tornar conscientes e, de certa forma, controláveis e modificáveis. Isso seria alcançado por meio de uma abordagem colaborativa e psicoeducativa (Knapp \& Beck, 2008). A esse respeito é possivel pensar em uma das distinções importantes entre a clínica de Beck e a de Freud: se para aquele autor os esquemas são passíveis de uma abordagem psicoeducativa, Freud (1911/1980j) é enfático ao afirmar que as pulsões sexuais não se educam, justamente porque podem funcionar por meio das fantasias.

É interessante indicar que as neurociências cognitivas têm se mostrado importante elo entre as teses psicanalíticas e os modelos de terapias cognitivas. Segundo Westen (2006), as terapias cognitivas têm considerado amplamente as declarações das neurociências cognitivas, segundo as quais a maioria dos processos mentais não alcançam a consciência. Tais declarações não deixam de ser referidas aos escritos freudianos, especificamente a aquele em que Freud (1950/1980c) busca descrever o aparelho mental a partir de um modelo de excitação neural. Da mesma forma, as neurociências cognitivas têm proposto o que Westen (2006) designa por certos refinamentos da técnica psicanalítica, justamente segundo afirmações dos modelos de terapias cognitivas.

Tais considerações mostram a fecundidade dos diálogos entre as teorias aqui referidas, revelando-se meio para o desenvolvimento de novas reflexões sobre a integralidade humana. Sem a pretensão de esgotar esse tema, este artigo indica pontos relevantes para tais diálogos, e que são corroborados por autores como Timary, Heenen-Wolff e Philippot (2011), que discutem a importância das representações para ambas as teorias. Cumpre ainda observar que a escolha de dois autores, Freud e Beck, não desconsidera a importância dos teóricos que avançaram ou deram novas interpretações aos conceitos de esquemas e de fantasias.

Considerando as diferenças e as aproximações (tanto teóricas quanto práticas) entre as teses de Freud sobre as fantasias e as teses Beck sobre os esquemas, fica salientada a importância da escuta da palavra do sujeito. E por que não dizer que, para ambos os autores, a realidade dos fatos é sempre vivida como realidade psíquica. 


\section{Referências}

Alford, B. A. \& Beck, A. T. (1997). The integrative power of cognitive therapy. Nova Iorque: The Guilford Press.

Beck, A. T. (1963). Thinking and depression. I. Idiosyncratic content and cognitive distortions. Archives of General Psychiatry, 9, 324-333.

Beck, A. T. (1964). Thinking and depression. II. Theory and therapy. Archives of General Psychiatry, 10, 561-571.

Beck, A. T., Rush, A. J., Shaw, B. F. \& Emery, G. (1997). Terapia cognitiva da depressão (S. Costa, trad). Porto Alegre: Artmed.

Beck, A. T. (2005a). The current state of cognitive therapy: a 40-year retrospective. Archives of General Psycbiatry, 62, 953-959.

Beck, A. T. (2005b). Além da crença: uma teoria de modos, personalidade e psicopatologia. Em P. M. Salkovskis (Ed.). Fronteiras da terapia cognitiva (pp. 21-40). São Paulo: Casa do Psicólogo.

Breuer, J. \& Freud, S. (1980). Estudos sobre a histeria (V. Ribeiro, Trad.). Em J. Salomão (Org.). Edição standard brasileira de obras completas de Sigmund Freud (Vol.II). Rio de Janeiro: Imago. (Original publicado em 1895).

Callegaro, M. M. (2005). A neurobiologia da terapia do esquema e o processamento inconsciente. Revista Brasileira de Terapias Cognitivas, 1(1), 9-20.

Callegaro, M. (2011). O novo inconsciente. Porto Alegre: Artmed.

D’ Avila Lourenço, L. C. (2000). O complexo de Édipo, na teoria de Jacques Lacan. (Dissertação de Mestrado). São Carlos: Universidade Federal de São Carlos Pós-Graduação em Filosofia e Metodologia das Ciências.

D’Avila Lourenço, L. C. (2005a). Transferência e complexo de Édipo, na obra de Freud: notas sobre os destinos da transferência. Psicologia: Reflexão e Critica, 18(1), 143-149.

D’Avila Lourenço, L. C. (2005b). A angústia, segundo Frend e Heidegger. Tese de Doutorado. Ribeirão Preto: Universidade de São Paulo - Programa de Pós-Graduação em Ciências.

Freud, S. (1980a). Repressão. Em J. Salomão (Org.), Edição standard brasileira de obras completas de Sigmund Frend (Vol. XIV, pp. 169-189). Rio de Janeiro: Imago. (Original publicado em 1915).

Freud, S. (1980b). Análise terminável e interminável. Em J. Salomão (Org.). Edição standard brasileira de obras completas de Sigmund Freud (Vol. XXIII, pp. 239-287). Rio de Janeiro: Imago. (Original publicado em 1937).

Freud, S. (1980c). Projeto para uma psicologia científica. Em J. Salomão (Org.). Edição standard brasileira de obras completas de Sigmund Frend (Vol. I, pp. 303-421). Rio de Janeiro: Imago. (Original publicado em 1950).

Freud, S. (1980d). Carta 69. Em J. Salomão (Org.). Edição standard brasileira de obras completas de Sigmund Freud (Vol. I, pp. 279-281). Rio de Janeiro: Imago. (Original publicado em 1950).

Freud, S. (1980e). Três ensaios sobre a teoria da sexualidade. Em J. Salomão (Org.). Edição standard brasileira de obras completas de Sigmund Freud (Vol. VII, pp. 129-249). Rio de Janeiro: Imago. (Original publicado em 1905).

Freud, S. (1980f). A dinâmica da transferência. Em J. Salomão (Org.). Edição standard brasileira de obras completas de Sigmund Freud (Vol. XII, pp. 131-143). Rio de Janeiro: Imago. (Original publicado em 1912).

Freud, S. (1980g). O ego e o id. Em J. Salomão (Org.). Edição standard brasileira de obras completas de Sigmund Freud (Vol. XIX, pp. 23-78). Rio de Janeiro: Imago. (Original publicado em 1923).

Freud, S. (1980h). Inibições, sintomas e ansiedade. Em J. Salomão (Org.). Edição standard brasileira de obras completas de Sigmund Freud (Vol. XX, pp. 95-203). Rio de Janeiro: Imago. (Original publicado em 1926).

Freud, S. (1980i). História de uma neurose infantil. Em J. Salomão (Org.). Edição standard brasileira de obras completas de Sigmund Freud (Vol. XVII, pp. 19-152). Rio de Janeiro: Imago. (Original publicado em 1918).

Freud, S. (1980j). Formulações sobre os dois princípios do funcionamento mental. Em J. Salomão (Org.). Edição standard brasileira de obras completas de Sigmund Freud (Vol. XII, pp. 277-289). Rio de Janeiro: Imago. (Original publicado em 1911).

Knapp, P. \& Beck, A. T. (2008). Fundamentos, modelos conceituais, aplicações e pesquisa da terapia cognitiva. Revista Brasileira de Psiquiatria, 30(Supl. II), S54-64.

Monzani, L. R. (1989). Freud: o movimento de um pensamento. Campinas: Editora da Unicamp.

Padesky, C. A. (2010). Aaron T. Beck: a mente, o homem e o mentor. Em R. L. Leahy (Org.). Terapia cognitiva contemporânea: teoria, pesquisa e prática (pp. 19-36). Porto Alegre: Artmed.

Ritvo, L. (1992). A influência de Darwin sobre Freud. Rio de Janeiro: Imago.

Timary, P., Heenen-Wolff, S. \& Philippot, P. (2011). The question of "representation" in the psychoanalytical and cognitive-behavioral approaches. Some theoretical aspects and therapy considerations. Frontiers in Psychology, 2(71), 1-8. 
Westen, D. (2006). Implications of research in cognitive neuroscience for psychodynamic psychotherapy. Focus, 4(2), 215-222.

Young, J. E., Klosko, J. S., Weishaar, M. E. (2008). Terapia do esquema: guia de técnicas cognitivocomportamenais inovadoras. Porto Alegre: Artmed.

Recebido em 09/08/2012 Reformulado em 05/02/2013 Aprovado em 25/03/2013

Sobre os autores:

Lara Cristina D’Avila Lourenço é psicóloga, doutora em Psicologia pela Universidade de São Paulo, mestre em Filosofia e Metodologia das Ciências, pela Universidade Federal de São Carlos, professora adjunta II do curso de Psicologia da Universidade Federal de São Paulo - Campus Baixada Santista.

Ricardo da Costa Padovani é psicólogo, doutor em Educação Especial pela Universidade Federal de São Carlos, especialista em Terapia Comportamental Cognitiva em Saúde Mental pelo Instituto de Psiquiatria HCFMUSP/Programa de Ansiedade, e professor adjunto II do curso de Psicologia da Universidade Federal de São Paulo - Campus Baixada Santista.

Contato com os autores:

Departamento de Saúde, Educação e Sociedade. Universidade Federal de São Paulo, Campus Baixada Santista Rua Silva Jardim, 136 - Vl. Mathias - CEP 11015-020 - Santos-SP, Brasil.

E-mail: ricardopadovani@yahoo.com.br 